\title{
LOS DERECHOS POLÍTICOS DE LA MUJER EN LA EVOLUCIÓN CONSTITUCIONAL URUGUAYA
}

Camila Umpiérrez Blengio*

\begin{abstract}
RESUMEN. El presente trabajo analiza la consagración de los derechos políticos de la mujer en el Uruguay, durante los siglos XIX y XX, desde una perspectiva jurídico-político-constitucional. Desarrolla una breve recorrida mundial acerca del movimiento feminista y la conquista de los derechos políticos de la mujer, para luego analizar las Constituciones Uruguayas de los años 1830, 1918 y 1934. El análisis constitucional se detendrá en el año 1934 en tanto la disposición constitucional referente a la ciudadanía se mantiene inalterada y las próximas Constituciones no hacen más que recogerla. Desde el mismo texto de la Constitución se presenta la situación de la época, el rol de la mujer en la sociedad uruguaya y las distintas posturas que surgieron respecto a la cuestión del sufragio femenino.
\end{abstract}

PALABRAS CLAVES. Constitución. Ciudadanía. Derechos políticos. Mujer. Reivindicación.

ABSTRACT. Throughout this paper, the embodiment of political rights of women in Uruguay will be analyzed, over the 19th and the 20th Centuries, and from a legal-political-constitutional perspective. A brief universal journey in relation to the feminist movement will be drafted, in order to later analyze the Uruguayan Constitutions of 1830, 1918 and 1934. Such constitutional analysis will end in 1934 as the constitutional provision regarding citizenship remains unchanged and therefore subsequent Constitutions do no more than to reflect it. From the text of the Constitution, this paper analyze the existing situation at that time, the role of women within Uruguayan society as well as the different stances that arose revolving around the issue of women's suffrage.

KEY WORDS. Constitution. Citizenship. Political Rights. Women. Assertion.

* Doctora en Derecho y Ciencias Sociales egresada de la Universidad de la República. Aspirante a Profesor Adscripto de Derecho Procesal, Facultad de Derecho, Universidad de la República. Correo electrónico: camila.umpierrez@hotmail.com 


\section{LAS CONQUISTAS POLITICAS DE LA MUJER EN EL MUNDO}

"El feminismo es una de esas tantas fuerzas que tienden a conquistar el nivel que por derecho le corresponde. No es la caprichosa y antojadiza de almas visionarias, sino que hunde sus raices en la realidad dolorosa y obscura de la misma vida". ${ }^{1}$

El camino hacia la consagración y reconocimiento de los derechos políticos de la mujer estuvo rodeado de obstáculos e impedimentos. Sin embargo, gracias a la lucha de destacados hombres y mujeres y luego de muchos años de reivindicaciones, la mujer consiguió ese derecho tan preciado y deseado: el derecho al voto. Esta conquista la llevaría a la esperanza y la búsqueda de la equiparación de todos sus derechos frente al hombre.

Como punto de partida, nos introduciremos en el siglo XIX. Tanto en Europa Occidental como en América del Norte, se dio inicio al movimiento feminista que luchó por la igualdad de derechos civiles y políticos de la mujer respecto del hombre.

El principal objetivo de la mujer fue la conquista del derecho al voto como primer paso para la consecución del resto de las conquistas en materia de derechos. En efecto, mediante el voto, la mujer obtenía la posibilidad de expresar sus opiniones y reivindicar sus derechos. En tanto la mujer no fuese considerada como ciudadana al igual que el hombre, su lucha no tendría fin.

Las palabras de Paulina Luisi, precursora de la lucha por los derechos políticos de las mujeres en el Uruguay, reflejan el significado de este movimiento:

"Quiere el feminismo demostrar que la mujer es algo más que materia creada para servir al hombre y obedecerle como el esclavo a su amo, que es algo más que máquina para fabricar hijos y cuidar la casa, que la mujer tiene sentimientos elevados y clara inteligencia, que si es su misión la perpetuación de la especie, debe cumplirla más que con sus entrañas y sus pechos: con la inteligencia y el corazón preparados para ser madre y educadora, que debe ser cooperadora y no la súbdita del hombre, su consejera y su asociada, no su esclava."

El primer país en consagrar el sufragio femenino fue Nueva Zelanda en el año 1893, gracias al movimiento liderado por la sufragista Katherine Sheppard (1847-1934). Con posterioridad, continúan la marcha por la aprobación del voto femenino países como Finlandia (1906), Noruega (1913), Dinamarca (1915), Reino Unido (1918), Alemania (1918), Estados Unidos (1920), España (1931), Francia (1944) e Italia (1945).

En Inglaterra la lucha por el sufragio femenino tuvo una gran importancia e influencia para el resto del mundo. Las primeras denuncias de la desigualdad aparecieron en el año 1792, en Londres, gracias a una mujer escritora y filósofa llamada Mary Wollstonecraft (1759-1797). A través de su obra "Vindicación de los Derechos de la Mujer" (A vindication of the rights of women) destaca el rol de la mujer en la sociedad y la necesidad del acceso

1 ALVAREZ VIGNOLI DE DEMICHELI, Sofía. Derechos civiles y políticos de la mujer. Discurso pronunciado en la Tercera Comisión de la VII Conferencia Panamericana en 1933, Montevideo, 1934, pág. 12.

${ }^{2}$ REVISTA ACCIÓN FEMENINA. Agosto 1917. Número 2. Año I. Montevideo. Página 48. 
a la educación a modo de que puedan contribuir a la sociedad. Es la obra que señala históricamente el inicio de la lucha por el voto en este país.

Asimismo, durante los años siguientes diversos movimientos sufragistas se fueron fundando y creciendo con la adhesión no solo de mujeres sino de célebres hombres como John Stuart Mill ${ }^{3}$ y Henry Fawset, quienes realizaron la primera petición en 1866 a la Cámara de los Comunes de Londres, por el reconocimiento y aprobación del sufragio femenino. Sin perjuicio de ello, no es hasta el año 1918, donde se permite que las mujeres inglesas mayores de 30 años pudieran votar, bajándose la edad a 21 años, en 1920.

En España la situación fue diferente y el proceso fue más lento. Las pioneras de los movimientos feministas fueron Concepción Arenal y Emilia Pardo. Esta última debió en 1841 disfrazarse de hombre para asistir a la Facultad de Derecho. A pesar de la tarea inagotable realizada por diversas mujeres fue recién en el año 1931 que se consiguió la aprobación del voto femenino.

En Francia, existieron fuertes movimientos que anteceden a la obtención del voto femenino. Ya en el año 1791, la escritora francesa Olympe de Gouges (1748-1793) redactó y presentó ante la Asamblea Nacional francesa su "Declaración de los Derechos de la Mujer y la Ciudadana", obra en la que postulaba la dignidad de las mujeres y por consiguiente, el reconocimiento de sus derechos y libertades fundamentales. Se dice que este documento constituye el paralelo femenino de la "Declaración de Derechos del Hombre y del Ciudadano" del año 1789. Sin embargo, transcurrió mucho tiempo para que estos postulados se hicieran realidad y en consecuencia, la mujer francesa votó por primera vez el 29 de abril de 1945 durante las elecciones municipales.

En América los primeros países en consagrar el derecho al voto, fueron Canadá en el año 1918 (salvo la provincia de Québec en el año 1952) y Estados Unidos en el año 1920. En este país ya se luchaba por la consecución de este derecho desde los primeros años de su vida independiente. Fue el Estado de Wyoming el primero en conceder el voto a las mujeres en 1869. Merece citarse, como luchadora destacada a Margaret Brent(1601-1671), inmigrante inglesa de la Colonia de Maryland, quien ya en 1647, abogó por un lugar en la legislatura.

Por último, cabe mencionar lo tardío de algunas aprobaciones del sufragio femenino como lo fueron la de Argentina en el año 1947, y que recién se puso en práctica en las elecciones del 11 de noviembre de 1951 cuando las mujeres votaron por primera vez.

\section{LA PERCEPCIÓN DE LA MUJER EN LA SOCIEDAD URUGUAYA: DISTINTAS OPINIONES ACERCA DEL VOTO FEMENINO.}

A fines del siglo XIX la cuestión del sufragio femenino fue abundantemente discutido. El ejercicio de los derechos políticos por parte de las mujeres se veía y se sentía de diversas

3 "Al manifestarme partidario del sufragio universal no tomo en consideración la diferencia de sexo. El sexo no debe influir en materia de derechos políticos, de la misma manera que no influye la estatura o el color de los cabellos. Todos los seres humanos tienen el mismo interés en ser bien gobernados, el bueno o el mal gobierno influye por igual en el bienestar de cada uno, cada uno, pues, necesita un sufragio para participar de sus beneficios. Si existe alguna diferencia esta está a favor de la mujer, porque siendo físicamente más débil necesita más la protección de las leyes". Cita en DELIO MACHADO, Luis. "Los derechos políticos de la mujer: el debate en torno al sufragio" en Revista de la Facultad de Derecho, No. 13 (enero-junio 1998). 
formas. Había quienes lo creían una amenaza para la familia, ya que el hogar y la maternidad conformaban la vida de la mujer en aquellos tiempos. Sin embargo, hubo quienes fervientemente lucharon por la aprobación del voto de la mujer en el Uruguay.

Dentro de los que apoyaban la tesis contraria de la igualdad política de la mujer, encontramos a Francisco DEL CAMPO, quien en el año 1880 expresaba lo siguiente:

"La mujer, ser débil por naturaleza, de sentimientos generosos, ángel enviado para endulzar la vida del hombre y estimularlo en el desarrollo de sus facultades, perdería esas preciosas dotes desde el momento que abriera su corazón a las impresiones politicas"."

Y afirmaba: "Razones muy poderosas me asisten para negarle el derecho a sufragar; no quiero entrar a considerar su naturaleza física porque los argumentos que podría deducir son bien conocidos y la moralidad me exige callarlos, examinaré no obstante su naturaleza moral y demostraré su gran inconveniencia. Dije anteriormente que la independencia era una de las condiciones que debía exigirse al elector. Pues bien, la mujer se encuentra en tales circunstancias que siempre será influenciada por algún ser querido y su voto no será la manifestación de la voluntad. Es en vano sostener que la mujer pueda mantenerse firme en el terreno de la política, y si por desgracia sucediera así, el hogar que debe ser el santuario de las buenas costumbres, se convertiría en teatro de hechos que degradarian a la familia, mirando por su base a la sociedad".

En la misma línea de pensamiento, Justino JIMÉNEZ DE ARÉCHAGA ${ }^{6}$ ilustraba en el año 1874, el rol de la mujer en la sociedad de su tiempo y la razón de la negación de sus derechos políticos, expresando que:

“.. Preguntó el Dr. Berra si creía que las mujeres tienen derecho al sufragio. El Dr. Aréchaga, con una sonrisa bastante expresiva y que demostraba toda la profundidad de sus convicciones, contestó negativamente y dijo: aun cuando reconocía en la mujer las mismas facultades y los mismos derechos del hombre, no le acordaba derechos politicos porque creía que la mujer tiene su misión especial en el hogar, y además porque los derechos políticos que no son otra cosa que la garantía de los derechos individuales sólo deben concederse a quienes no pueden dañar con su ejercicio la colectividad, que dado el actual estado de las sociedades es indudable que la mujer, cuya educación social no ya política ha sido completamente descuidada, no ofrece garantias para ejercitar con acierto e independencia el derecho de sufragio" (...) "reputaba de más alta importancia social la conservación de la familia que la concesión de derechos políticos de la mujer"»

${ }^{4}$ DEL CAMPO, Francisco. Naturaleza y Extensión del sufragio, Imp. Liberal, Montevideo, 1880, pág. 14, cita en DELIO MACHADO, Luis. "Los derechos políticos de la mujer: el debate en torno al sufragio" En Revista de la Facultad de Derecho, No. 13 (enero-junio 1998).

${ }^{5}$ DEL CAMPO, Francisco. Naturaleza y Extensión del sufragio, Imp. Liberal, Montevideo, 1880, pág. 15, cita en DELIO MACHADO, Luis. "Los derechos políticos de la mujer: el debate en torno al sufragio" En Revista de la Facultad de Derecho, No. 13 (enero-junio 1998).

${ }_{6}^{6}$ Justino Jiménez de Aréchaga Moratorio, 1850-1904, abogado, profesor de Derecho Constitucional.

${ }^{7}$ Refiere al concurso de oposición para promover la cátedra de Derecho Constitucional en el año 1874, en el que se analizó el sufragio popular. Hicieron oposición los Dres. Aréchaga y Berra, componiendo el tribunal los doctores Eduardo Brito del Pino, José María Muñoz, Ambrosio Velazco, Martín Aguirre, Ildefonso García Lagos, y José Sienra Carranza. En “Analectas. Concurso para promover la cátedra de Derecho Constitucional en 1874”, REVISTA HISTÓRICA. Tomo LIV, Año LXXV, Nos. 160-162, Publicación del Museo Histórico Nacional. Pivel Devoto, Juan - Director. Año 1982.

8 REVISTA HISTÓRICA, Concurso para promover la cátedra de Derecho Constitucional en 1874. Tomo IV, Montevideo, 1982, p.485 
En contraposición con estas opiniones, mencionaremos a los partidarios del derecho al sufragio femenino de la mujer al voto.

ElDr. Francisco Antonio Berra, le replicaba al Dr. Jiménez de Aréchaga que: "la mujer tiene la misma naturaleza del hombre, los mismos derechos naturales y las mismas facultades, no podrá negársele el ejercicio del derecho de sufragio que es un derecho natural y que la mujer, como el que más tiene interés en ejecutar para asegurar la tranquilidad del hogar, el bienestar de la familia y la mayor suma de regalias y prerrogativas para sus hijos, su esposo y sus hermanos. "

Asimismo, figuras políticas como Baltasar BRUM, defensor de los derechos políticos de la mujer, expresaba en 1923 que:

"Los enemigos del voto de la mujer sostienen que no debe permitírsele que vote porque no tiene inclinaciones políticas, porque no ha actuado nunca o lo ha hecho muy contadas veces en la vida pública, y porque carece de experiencia sobre negocios del Estado... Son esos, razonamientos falsos, y además, desleales. Los hombres no pueden inculparle la falta de experiencia politica porque ellos mismos se han encargado de impedir que la adquiriera. ¿Cómo podría la mujer tener hábitos democráticos y conocimiento de la ciencia de gobierno, si nunca se la ha dejado sufragar y si se le han clausurado todas las vías de acceso a la dirección de los intereses comunes?

Se teme que el reconocimiento del voto a la mujer destruya lo que se llama "femininidad", es decir, lo que es en ella suave, delicado y sensible. Se atribuye al sufragio el efecto maligno de crear tipos duros y fríos de mujer. Pero no es así, la función del voto no demanda el sacrificio de la belleza, ni de la sensibilidad.

Los enemigos del feminismo han tratado de combatirlo con el arma grosera innoble del ridiculo, publicando caricaturas en que se deforma la belleza o elegancia de las mujeres dedicadas a la propaganda feminista. Esa actitud es injusta, porque no se puede desconocer la enorme cantidad de mujeres hermosas, elegantes y cultas que luchan por el sufragio, convencidas de que con ello elevan la dignidad de su sexo." 10

Y por último, cabe destacar la postura de Emilio FRUGONI quien afirmaba:

"Yo llamo la atención de los que aqui expresan el temor de que la política destruya en el sexo femenino las tradicionales virtudes domésticas. Yo las reconozco también como muy apreciables, siempre, claro está, que no quiera transformárselas en obstáculo a la elevación jurídica, política e intelectual de la mujer"1

\section{LA CONSTITUCIÓN DE 1830}

Héctor Gros ESPIELL señala en su obra "Evolución constitucional del Uruguay” que "la labor realizada por los primeros constituyentes con los elementos doctrinarios y de

9 REVISTA HISTÓRICA. Tomo LIV, Año LXXV, Nos. 160-162, Publicación del Museo Histórico Nacional. Pivel Devoto, Juan - Director. Año 1982, pág. 484 y 485.

${ }^{10}$ BRUM, Baltasar. Los derechos de la mujer: reforma a la legislación civil y politica del Uruguay. Editor José María Serrano, Montevideo, 1923, pág. 51, 52 y 53.

${ }^{11}$ FRUGONI, EMILIO. La mujer ante el Derecho. Los derechos políticos de la mujer. Editorial Indoamericana, Montevideo, 1940, pág. 180. 
derecho comparado que poseían, fue extraordinaria. Con ellos elaboraron un texto constitucional que adoptaba las soluciones más ponderadas y estimables de todo el derecho constitucional de la época, redactando la Constitución en un lenguaje técnico preciso y acertado, dentro de una estructura armónica y sabia"12.

En efecto, la Constitución de 1830 tuvo en el Uruguay magníficas repercusiones. Tanto es así, que nuestra Constitución actual conserva la estructura original y muchas de sus disposiciones inalteradas.

Sin embargo, no debemos olvidar, que en lo relativo al electorado y la ciudadanía el texto constitucional fue muy limitado e inflexible. En este sentido, la Constitución de 1830 estableció condiciones muy duras para la sociedad, las cuales llevaron a excluir de la ciudadanía a un porcentaje altísimo de la población uruguaya, entre ellas, la protagonista de este trabajo: la Mujer.

Adentrándonos en el estudio de la Constitución de 1830, debemos remitirnos a la Sección II titulada "De la ciudadanía, sus derechos, modos de suspenderse y perderse", Capítulo I y II. La misma estaba dedicada a la ciudadanía, delimitando quienes eran ciudadanos, clasificándolos en naturales y legales, los modos de adquisición de la ciudadanía por extranjeros, las causales de suspensión y pérdida y los derechos inherentes a la ciudadanía.

Respecto a la ciudadanía natural, la Constitución establecía en su artículo 7:

"Ciudadanos naturales son todos los hombres libres, nacidos en cualquier punto del territorio del Estado".

De acuerdo al artículo 11 de la Constitución, la ciudadanía se suspendía por las siguientes razones:

1. Por ineptitud física o moral, que impida obrar libre y reflexivamente,

2. Por la condición de sirviente a sueldo, peón jornalero, simple soldado de línea, notoriamente vago o legalmente procesado en causa criminal, de que pueda resultar pena corporal o infamante,

3. Por el hábito de ebriedad,

4. Por no haber cumplido veinte años de edad, menos siendo casado desde los 18 ,

5. Por no saber leer ni escribir, los que entren al ejercicio de la ciudadanía el año 1840 en adelante,

6. Por el estado de deudor fallido, declarado tal por juez competente,

7. Por deudor al Fisco, declarado moroso

Vemos entonces que, en el régimen constitucional de 1830, la ciudadanía estaba ligada a la condición inexorable de "hombre libre".

Esta expresión fue fruto de largos debates entre famosas figuras masculinas de la época acerca del verdadero significado de esta expresión tan controvertida. En efecto, la cuestión

${ }^{12}$ GROS ESPIELL, HÉCTOR. Evolución constitucional del Uruguay. FCU, 3era. Edición, Montevideo, 2003, pág. 41. 
radicaba en desvelar qué se entendía por la expresión “hombres libres” y si la misma incluía o no al sexo femenino ${ }^{13}$.

Asílo planteaba Justino Eugenio JIMÉNEZ DE ARÉCHAGA, Catedrático de Derecho Constitucional ${ }^{14}$, en su obra "El voto de la mujer: su inconstitucionalidad":

“¿Cabe la indistinción sexual en la expresión "todo hombre libre" que adopta la Constitución para determinar la primera y más esencial condición de la ciudadanía y el electorado?; ¿De dónde ha sido adoptada esa expresión y cuál es su significado?"15

Algunos autores de la época afirmaron que esta expresión de "hombres libres" no excluía a la mujer, ya que la palabra "hombres" refería a un concepto amplio del mismo, que abarca ambos sexos, tanto femenino como masculino. Fundaban su argumentación en que la Sección XI de la Constitución de 1830 se emplea el término genérico "hombres" -y no "hombres libres"- para afirmar derechos de la personalidad que no pueden reconocer distinciones de $\operatorname{sexo}^{16}$.

No obstante, otros autores sostenían lo contrario.

En efecto, Justino E. Jiménez de Aréchaga ${ }^{17}$ expresaba que en la Sección XI de la Constitución, los términos "hombres", "ciudadanos", "habitantes" e "individuos" (arts. 130, $132,134,135,140,142,146$ y 147) tienen la misma significación pero no por eso es la misma identificación cuando se trata de disposiciones que regulan derechos políticos. La ciudadanía no ha sido para nuestros constituyentes el hecho de la naturaleza sino la obra de la ley, por lo que el goce y el ejercicio de los derechos del elector no pertenecen más que a los que son expresamente designados por la ley. Y concluía: "De lo expuesto resulta que la mujer no integra los cuadros de la ciudadanía y por consiguiente del electorado porque ella no ha sido expresamente incluida en aquellos por la Asamblea de 1828 y porque esa inclusión repugna al texto, al espíritu y a los antecedentes de la Constitución. La mujer no es, pues, en nuestro país, sujeto de Derecho Público ya que no basta a tal fin referir a ella las garantías constitucionales de la sección XI que no han necesitado ser expresadas para que la libertad civil contara con la garantía del poder jurisdiccional". ${ }^{18}$

13 Recordemos que el derecho constitucional rioplatense fue la fuente más importante de la Constitución de 1830, y en especial, la Constitución Argentina del año 1826 que fue un antecedente inmediato de la nuestra, y que establecía: "artículo 4 - Son ciudadanos de la nación argentina, primero, todos los hombres libres (...)”, “artículo 6 - Se suspende la ciudadanía por no haber cumplido los 20 años siendo soltero, por no saber leer ni escribir”. Al respecto señalaba JIMÉNEZ DE ARECHAGA que: "adoleciendo de la misma deficiencia formal que nuestra Constitución, solo considera hombres libres a los que tengan más de veinte años salvo siendo casados y sepan leer y escribir, condiciones necesarias para el electorado". JIMENEZ DE ARECHAGA, Justino E. El voto de la mujer: su inconstitucionalidad. Peña Hermanos - Impresores. Montevideo, 1915, pág. 32.

14 Justino Eugenio Jiménez de Aréchaga Vargas, 1883 - 1928.

15 JIMENEZ DE ARECHAGA, Justino E. El voto de la mujer: su inconstitucionalidad. Peña Hermanos - Impresores. Montevideo, 1915, pág.30

${ }^{16}$ Ob. Cit. nota 15 , pág. 59

17 En su obra "El voto de la mujer: su inconstitucionalidad", se encuentra una investigación pormenorizada sobre la expresión "hombres libres" en ciertos países, tales como Argentina, donde Aréchaga señala que "la mujer no fue, pues, "hombre libre" en el espíritu de los constituyentes argentinos, en la historia política de las provincias." (pág. 35), en España donde señala que "hombre libre fue igualmente concepto jurídico excluyente de los individuos del sexo femenino en las instituciones civiles y políticas de España, de aplicación general en la Metrópoli y en sus colonias y vigentes aun las primeras después de la revolución americana bajo el imperio de las legislaciones independientes (pág. 45).

${ }^{18}$ Ob. Cit. nota 15, pág. 62. 
En definitiva y sin perjuicio de estas discusiones doctrinarias, la expresión "hombre libre" adoptada en nuestra Constitución de 1830 fue tomada como concepto jurídico excluyente de los individuos del sexo femenino. En consecuencia, en la Constitución de 1830 la mujer no era ciudadano.

\section{CONQUISTAS POLÍTICAS DE LA MUJER EN EL URUGUAY DURANTE 88 AÑOS (1830 - 1918)}

\subsection{Las primeras conquistas femeninas}

Diversos autores han manifestado que los constituyentes de 1830 erraron al dictar las disposiciones sobre la ciudadanía, en tanto la Constitución había sido excesivamente parca en el reconocimiento de la calidad de ciudadanos ${ }^{19}$.

Desde los primeros años de su vigencia, la Constitución de 1830 fue infringida y desvirtuada por prácticas que se desenvolvían a su margen.

En efecto, muchas de las restricciones impuestas por el texto constitucional no funcionaron en la práctica, porque por medio de normas legislativas, de más que dudosa constitucionalidad, se soslayó la rigidez de algunas de estas disposiciones ${ }^{20}$. Se manifestaron, a su vez, aspiraciones reformistas de toda índole. A pesar de todo esto, ella misma resistió a todos los intentos de reforma ordenada hasta el proceso constituyente que comenzó en la segunda década del novecientos.

En cuanto a la ciudadanía, la mayor preocupación fue la de ampliar el cuadro de ciudadanos. Esto se obtuvo mediante la aprobación de algunas leyes que facilitaron el ingreso de los extranjeros a la lista de los ciudadanos ${ }^{21}$ así como las que eliminaron algunas de las causales de suspensión de la ciudadanía previstas por el texto constitucional.

Entre las conquistas femeninas durante los 88 años de vigencia de la Constitución de 1830 mencionaremos las siguientes:

Se estableció por ley el derecho a la licencia por maternidad (1911), se aprobó la ley del divorcio por la sola voluntad de la mujer (1912), a nivel laboral se dispuso que las mujeres y los niños quedaban excluidos de realizar tareas peligrosas (1914), se dictó la ley que estableció la obligatoriedad de que en los lugares de trabajo se debía disponer de sillas para que las mujeres pudieran realizar las tareas sentadas, conocida como la "Ley de la Silla" (1918).

\subsection{Proyectos de ley sobre el sufragio femenino y el debate sobre su constitucionalidad.}

Desde el año 1914 hasta la fecha de aprobación de la ley de voto femenino en el año 1932, se presentaron una gran cantidad de proyectos de ley sobre sufragio femenino e igualdad de derechos civiles y políticos.

${ }^{19}$ JIMENEZ DE ARÉCHAGA, Justino. La Constitución Nacional. Tomo I, pág. 77.

${ }^{20}$ JIMENEZ DE ARÉCHAGA, Justino. La Constitución Nacional. Tomo I, pág. 77.

${ }^{21}$ Leyes de 1853 y de 1874 citadas en JIMENEZ DE ARÉCHAGA, Justino. La Constitución Nacional. Tomo I., pág. 80. 
El primero de estos proyectos fue elaborado por el Dr. Héctor Miranda, representante colorado del departamento de Treinta y Tres en el año 1914, que fuera el referente principal de los que le precedieron. Entre los proyectos posteriores se destaca el de Emilio Frugoni y Celestino Mibelli del año 1920, el proyecto de César Miranda del mismo año, el proyecto de Baltasar Brum del año 1921 y el proyecto del Herrerismo del año 1931.

El primer proyecto de ley presentado en el año 1914 creó una atmósfera de controversia y disputa nunca antes vista. Contra el mismo, se formuló por parte de Justino E. Jiménez de Aréchaga la objeción de que era inconstitucional ${ }^{22}$. Este jurista sostuvo que cualquier ley que le conceda el derecho al sufragio a la mujer sería inconstitucional por el simple hecho de que la propia Constitución ha determinado que solo los hombres libres son ciudadanos naturales. En consecuencia, una ley -de menor jerarquía que la Constitución- no puede establecer algo que la Constitución no habilita, siendo contraria a esta última y por lo tanto, inconstitucional.

Al respecto, se transcriben algunos párrafos de la obra de J. DE ARÉCHAGA:

"La limitación del sufragio, ha escrito el Doctor Héctor Miranda, no nace ni de la letra ni del espíritu de la Constitución sino de la arbitrariedad de los glosadores, no la Constitución sino la costumbre política ha decretado la anormalidad de que todos los hombres que no tengan ciertas incapacidades extremas posean la plenitud de los derechos políticos y no disponga de ellos la mujer, sean cuales fueren sus condiciones intelectuales o morales. El sufragio-derecho político o el sufragio-función pública debe corresponder a todos los seres humanos o a todos los capaces. Nuestros constituyentes conocieron o no las reivindicaciones feministas de la Francia revolucionaria, pero ello queda indiferente en cuanto a la constitucionalidad de tales reivindicaciones desde que, no existiendo a su respecto una declaración prohibitiva que limite en tal sentido la acción de la ley ordinaria, ésta es obligada por el imperativo de la libertad"23.

"No incluida la mujer en la sociedad politica del Poder Constituyente, excluida por el espíritu de la Carta: ¿puede el Poder Legislativo, en uso de su función privativa de legislar, sustituirse al Poder Constituyente, integrar la sociedad politica que representa, desviarse de las normas constitucionales para cambiar, por extensión, el asiento mismo de la soberania?"24

"Las Constituciones -concluíamos- son inmutables e inviolables para los gobiernos y para los pueblos mientras estos no proclamen que su luz se ha extinguido, que la esencia que las anima no es su propia esencia, que el orden que regulan e imponen como expresión de la conciencia popular no es compatible con las nuevas aspiraciones de la soberanía.

Ynada podrá modificar este criterio mientras se mantenga la adhesión a los principios del gobierno representativo, y en tanto haya una Constitución, superior a la ley ordinaria, que determine los legítimos dominios de la ley"25.

${ }^{22}$ Se puede estudiar su posición en el capítulo III titulado "La Constitución y la Ley", de su obra " $E l$ voto de la mujer: su inconstitucionalidad", Peña Hermanos - Impresores. Montevideo, 1915.

${ }^{23}$ Ob. Cit. nota 15 , pág. 3

${ }^{24} \mathrm{Ob}$. Cit. nota 15, pág. 63

${ }^{25} \mathrm{Ob}$. Cit. nota 15, págs. 68 y 69. 
Y concluye: "Así pues, en tanto los sostenedores del proyecto del doctor Héctor Miranda no nos demuestren que el proyecto de ley de sufragio de la mujer está incluido en uno de los incisos del artículo 17 de la Constitución, que determina taxativamente las facultades propias del Poder Legislativo, lo que creemos superior a todo esfuerzo dialéctico, podremos decir de esa iniciativa que ella no es la de un legislador de la República sino de la de un miembro de la Convención, depositario de la soberanía nacional." ${ }^{\text {26 }}$.

Debido a las numerosas críticas que recibió el proyecto de ley y la muerte prematura de su autor, algunos meses después de presentado en el Parlamento, se detuvo el estudio del proyecto de ley.

Sin perjuicio de que esto, la iniciativa del diputado Miranda fue determinante para comenzar a tratar este tema en el Parlamento, en el sentido de hacer desaparecer cualquier traba de carácter constitucional que obstara al reconocimiento de los derechos políticos de la mujer, dejando al Poder Legislativo la facultad de acordarlo cuando lo estimare oportuno.

\subsection{Asociaciones de mujeres. La figura destacada: Dra. Paulina Luisi}

En el Uruguay la fundación de las más antiguas sociedades feministas se produce en el año 1916, éstas son: "La Alianza uruguaya de Mujeres" que presidía la Dra. Paulina Luisi y el "Consejo Nacional de Mujeres del Uruguay". Ambas asociaciones constituyeron el engranaje fundamental para la final consagración del derecho al voto femenino. Realizaron incesantes actividades y consiguieron congregar a cientos de mujeres uruguayas, que todas unidas, hicieron escuchar sus voces.

Paulina Luisi fue en el Uruguay una de las figuras femeninas más destacadas en la lucha por los derechos políticos de la mujer. Fue Presidenta fundadora de la Alianza Uruguaya y del Consejo Nacional de Mujeres, miembro de la Directiva de la Unión Mundial para los derechos ciudadanos de la mujer, delegada del Gobierno del Uruguay a la Comisión de Protección a la Infancia y la Juventud en la Liga de Naciones, Presidenta de su Comisión mundial para la moralidad pública.

Una pequeña biografía sobre esta mujer y a su vez, una mirada acerca del sentimiento de otras mujeres respecto de ella, lo encontramos en el libro "Matilde, la mujer de Batlle" de Mercedes VIGIL, en el cual expresa:

"El número que leía ahora Matilde traía un sabroso reportaje a Paulina Luisi, a quien Matilde apreciaba mucho y que desde hacía bastante tiempo había despertado su admiración.(...)

Matilde recordaba que hacía más de treinta y cinco, un italiano afincado en Paysandú desde la década de 1870 había fundado, apoyado por su logia, el primer hospital de sangre del país, para socorrer a los heridos de la revolución del Quebracho.

Aquel italiano, se había casado con una maestra que siempre habia luchado por los derechos de la mujer. Ambos se establecerían, años después, en Montevideo, y sus seis hijas mujeres serían piezas destacadas en ese difícil tránsito de la mujer uruguaya hacia la modernidad.

\footnotetext{
${ }^{26}$ Ob. Cit. nota 15, pág. 74.
} 
Paulina, la mayor, maestra de profesión, había sido en 1908, con treinta y tres años, la primera mujer en obtener el título de doctor en Medicina y Cirugía del país.

Este hecho habia tenido fundamental importancia, sobre todo considerando que apenas un par de años antes, se le negaba el derecho a rendir exámenes de bachillerato a Luisa Domínguez.

Para justificar tal medida, el conocido jurista doctor Antonio Vigil, en representación del Consejo Universitario, fundamentaba: "Hacer cocido y hacer calceta; la olla y la aguja: he alli el horizonte obligado de nuestras mujeres, cualquiera sea su posición social, sus tendencias y aptitudes”.

Paulina Luisi, de carácter firme y decidido, se dedicó a la obstetricia y recibió rápidamente la confianza de muchas mujeres que rehusaban dejarse examinar por médicos hombres.

De activa militancia social, Paulina Luisi fue fundadora, junto con Emilio Frugoni, del Partido Socialista. Durante las primeras décadas del siglo XX, apoyó la fundación de diversos organismos en defensa del derecho femenino y las fundaciones gremiales, como la Unión de Telefonistas y las Costureras de Sastrería"27.

Por su fundamental importancia para la búsqueda y final conquista del derecho al sufragio femenino, se designó con el nombre de "Doctora Paulina Luisi", el Hospital de la Mujer, del Centro Hospitalario Pereira Rossell (Ley N 17.900).

\section{LA CONSTITUCIÓN DE 1918}

\subsection{El artículo 10 de la Constitución de 1918 y la Ley N8.927 de 1932}

El 3 de enero de 1918 es promulgada una nueva Constitución, la cual entra en vigencia el 1 de marzo de 1919 (disposición transitoria, letra A).

La Constitución de 1918 democratizó y amplió las disposiciones anteriores respecto a la ciudadanía. Merece destacarse la modificación que suprimió las normas incluidas en la Constitución de 1830 por las cuales se suspendía la ciudadanía a los peones jornaleros, vagos, ebrios habituales, analfabetos, sirvientes a sueldo, fallidos y deudores morosos del fisco. Estas reformas tuvieron gran importancia ya que acentuaron el carácter democrático del régimen, eliminando todo vestigio de sistema censitario ${ }^{28}$.

En cuanto a la reforma relativa al voto de la mujer, esta Constitución, aunque no otorgó directamente la ciudadanía a la mujer, estableció que por ley se le podría reconocer el derecho al voto activo y pasivo. En efecto, el Constituyente dispuso en su artículo 10:

"El reconocimiento del derecho de la mujer al voto activo y pasivo, en materia nacional o municipal, o en ambas a la vez, solo podrá ser hecho por mayoría de dos tercios sobre el total de los miembros de cada una de las Cámaras”.

${ }^{27}$ VIGIL, Mercedes. "La vanguardia feminista" en Matilde, la mujer de Batlle. Editorial Planeta, Montevideo. 1era. edición, 2003, págs. 258 - 260.

${ }^{28}$ GROS ESPIELL, Héctor. Evolución Constitucional de Uruguay. FCU, Montevideo. 3era. edición, 2003, pág. 69 . 
Al respecto, se transcribe un pasaje de un artículo de la Revista Acción Femenina que refleja el sentir de las mujeres en este momento: "La ratificación popular de la nueva Constitución, cuyas bases principales han sido planteadas en el acuerdo celebrado por los partidos políticos de nuestro país, ha modificado de una manera favorable la situación política de la mujer respecto a las posibilidades de su emancipación política. La nueva Carta Constitucional de la República, al dejar una posibilidad a la emancipación, ha puesto tales dificultades que se necesitarán muchos esfuerzos y mucha constancia para conseguirla!'”29

Finalmente, el 16 de diciembre de 1932, por Ley $\mathrm{N}^{\circ} 8.927$ se consagraron los derechos políticos de la mujer.

En su artículo primero expresa: "Reconócese el derecho de la mujer el derecho al voto activo y pasivo, tanto en materia nacional como municipal" y en su artículo 2: "Declárase aplicable a la mujer todas las disposiciones legales de carácter electoral en vigor".

\subsection{El primer voto femenino en Uruguay y América Latina en el año 1927.}

Sin perjuicio de que el primer voto femenino oficial en elecciones nacionales en Uruguay se realizó en el año 1938, el 3 de julio de 1927 se realizó un plebiscito en Cerro Chato, en virtud del cual las mujeres votaron por primera vez en nuestro país y en América Latina. En este plebiscito se votó para decidir la situación geopolítica de la Villa, ubicada en el cruce de tres departamentos; Treinta y Tres, Florida y Durazno en el km 260 de la Ruta 7. A través del mismo se debía decidir si Cerro Chato pasaría a pertenecer a un solo departamento o seguiría en la misma situación en la cual se encontraba ${ }^{30}$.

La Corte Electoral dictó un decreto con fecha mayo 31 de 1927, donde se autorizaba la realización del plebiscito, señalando en su artículo 10: "Las personas sin distinción de nacionalidad y sexo que deseen intervenir en el plebiscito deberán inscribirse previamente en el Registro que abrirá la Comisión Especial Parlamentaria”.

La votación se cumplió el domingo 3 de julio de 1927, mediante voto secreto observando todas las formalidades que al respecto establecía la Ley de Elecciones, incluyendo el voto femenino.

Esta votación significó el ejercicio del derecho al voto femenino por primera vez en América del Sur.

Como forma de homenaje de este acontecimiento, por Ley $\mathrm{N}^{\circ} 18.148$ del 2 de julio de 2007 se declaró: "feriado no laborable para la villa Cerro Chato, ubicada en la $6^{a}$ Sección Judicial del departamento de Treinta y Tres, $4^{a}$ Sección Judicial del departamento de Florida y $8^{a}$ Sección Judicial del departamento de Durazno, el día 3 de julio de 2007, con motivo de conmemorarse los ochenta años de la realización del plebiscito donde votó por primera vez la mujer en el Uruguay" (artículo 1).

${ }^{29}$ REVISTA ACCIÓN FEMENINA. Diciembre de 1917. Número 6, año I. Montevideo, pág. 184.

${ }^{30}$ AMARILLO, Solana; DELOS, Gisele y FERNANDEZ, Jessika. "Sufragio femenino" en Revista de la Facultad de Ciencias Jurídicas. Vol. 2, N², 2009. 


\section{LA CONSTITUCIÓN DE 1934}

\subsection{La Constitución de 1934 y su artículo 65}

La Constitución de 1934 abandonó toda diferencia entre el hombre y la mujer en lo que se refiere a los derechos políticos. Si bien la ley N 8.927 de 16 de diciembre de 1932 había reconocido la ciudadanía a la mujer, de acuerdo con la autorización establecida por el artículo 10 de la Constitución de 1918, la Carta de 1934, superó esta etapa modificando los textos anteriores en el sentido de equiparar la situación del hombre y de la mujer frente a la ciudadanía y sus derechos. Desde entonces, nuestro derecho constitucional no ha variado al respecto. ${ }^{31}$

Esta reforma constitucional consagró el concepto amplio de la ciudadanía:

"Artículo 65.- Ciudadanos naturales son todos los hombres y mujeres nacidos en cualquier punto del territorio de la República. Son también ciudadanos naturales los hijos de padre o madre orientales, cualquiera haya sido el lugar de su nacimiento, por el hecho de avecindarse en el país e inscribirse en el Registro Cívico".

\subsection{La votación del 27 de marzo de 1938.}

Después de muchos años de movilizaciones a lo largo y ancho del país, las mujeres pudieron votar por primera vez en los comicios del domingo 27 de marzo de 1938.

Fue un día histórico en el que la mujer uruguaya pudo por primera vez en todo el país, hacer escuchar su voz y pronunciarse en las urnas, ejerciendo ese preciado y anhelado derecho a sufragar por el cual habían luchado durante tantos años.

Fue un domingo de alegría y de festejo en el cual la mujer pudo manifestarse en la vida cívica y política al igual que el hombre, en un pie de igualdad nunca antes vivido por nuestra sociedad uruguaya. Un 27 de marzo de 1938 que ninguna mujer de la época olvidaría y que pasaría a marcar la historia uruguaya.

A efectos de proporcionar una visión exacta de lo que sucedió ese domingo de votación, se destacan algunos de los textos publicados en diarios de la época.

Por ejemplo, el artículo titulado "La mujer en el sufragio" que fuera publicado en el Diario La Mañana:

"Por primera vez, la mujer uruguaya intervino ayer en los pronunciamientos de la soberanía nacional, concurriendo a los atrios electorales en el uso de los derechos civiles que la ley le ha concedido.

Ypor cierto, que esa iniciación en las contiendas comiciales la presenta poseída de una clara unción de sus deberes cívicos y de una cultura democrática que mucho dice.

Con la misma decisión, entusiasmo y fuerte voluntad con se la vio intervenir dentro de los diversos sectores de opinión en las asambleas partidarias durante largos meses, acudió ayer, desde la primera hora a las mesas receptoras de votos a sufragar, a integrar las propias mesas, a controlar como delegadas de los partidos políticos y por fin, actuar en todas las manifestaciones cívicas.

${ }^{31}$ GROS ESPIELL, Héctor. Evolución Constitucional de Uruguay. FCU, Montevideo. 3era. Edición, 2003, pág. 82 
Si alguna comprobación era necesaria de ventajas que recibiría el ambiente nacional del voto de la mujer quedó ayer bien en evidencia, con verdadero enaltecimiento de sus aptitudes y virtudes para la acción cívica"32.

En cuanto a la cantidad de mujeres que votaron, el Diario La Mañana expresó:

"Cosa difícil de precisar la cantidad de mujeres que han votado. Hay inscriptas, en Montevideo, 66.079. A juzgar por la actividad desarrollada desde los primeros instantes, puede asegurarse que por lo menos lo han hecho el 80 \% de las mismas, o más.

El pasaje por las mesas receptoras nos ponía de continuo frente a la realidad. Igual cantidad de mujeres que de hombres esperando su turno.

La mujer ha dado un alto ejemplo de civismo"»3.

Asimismo, en el Diario El debate se publicó el siguiente extracto:

"El debut cívico de la mujer, justo es reconocerlo, superó las previsiones más optimistas.

Puede asegurarse que las mujeres votaron en gran cantidad.

El debut ha sido, pues, feliz"34.

\subsection{Las razones por las que la mujer no ejerció el derecho al voto previo al año 1938}

Surge de este análisis la siguiente interrogante: ¿Por qué la mujer no pudo votar antes del año 1938, en el procedimiento de reforma de la Constitución de 1934, habiéndose reconocido su derecho al sufragio por ley en el año 1932?

Pues bien, cabe recordar que la tercera Constitución uruguaya nació del golpe de Estado de fecha 31 de marzo de 1933, no habiéndose cumplido con el procedimiento de reforma de la Constitución que preveía la Constitución de $1918^{35}$. Por el contrario, se autorizó la ratificación popular. En efecto, por Decreto- Ley $N^{\circ}$ 9.038, dictado por la Asamblea deliberante el 16 de mayo de 1933, se convocó a elecciones de la Convención Constituyente, estableciéndose que "la Constitución que sancione la Convención Nacional Constituyente será sometida a un plebiscito de ratificación (art. 20), que se consideraría aprobatorio si resultaran por si la mayoría de los votos emitidos en el plebiscito”(art. 21).

Fue así que la Convención Nacional Constituyente aprobó el Proyecto de Reforma el 24 de marzo de 1934, el plebiscito de ratificación se realizó el 19 de abril de 1934, resultando aprobatorio y fue promulgada por la Convención Nacional Constituyente el 18 de mayo de

${ }^{32}$ Diario La Mañana. "La mujer en el sufragio". Fecha: 28 de marzo de 1938.

${ }^{33}$ Diario La Mañana. "Es imposible precisar cuántas mujeres han votado". Fecha: 28 de marzo de 1938

${ }^{34}$ Diario El Debate. Fecha: 28 de marzo de 1938.

${ }^{35}$ El procedimiento de reforma de la Constitución de 1918 establecido en los artículos 177 y 178, exigía dos legislaturas: la primera tenía la iniciativa y debía aprobar las enmiendas por dos tercios de votos del total de componentes de cada Cámara, la segunda debía ratificar dichas enmiendas. Se eliminaba de este modo el sistema de Convención Constituyente y de ratificación popular que había adoptado la ley de 1912 con la cual se había podido modificar la Constitución de 1830. 
1934. Para ese entonces, aun no se habían destinado los recursos necesarios para que las mujeres accedieran al Registro Cívico Nacional ${ }^{36}$, lo cual recién sucedió en el año $1935^{37}$. Por esta razón de carácter administrativo, las mujeres no pudieron ejercer el derecho al voto en el año 1934, pese a existir la ratificación popular.

\subsection{El ingreso de la mujer al Parlamento por primera vez}

La consagración de la ciudadanía de la mujer uruguaya, no solo posibilitó el ejercicio del derecho al voto, sino que también la facultad de postularse para cargos públicos y la participación en la vida política del país, de la cual habían sido dejadas al margen durante toda la vida independiente del Uruguay.

Las mujeres ingresaron al Parlamento por primera vez en la historia uruguaya en el año 1942. Fueron las diputadas Julia Arévalo de Roche (partido socialista) y Magdalena Antonelli Moreno (partido colorado), y las senadoras Sofía Álvarez Vignoli de Demichelli (en representación del Riverismo), e Isabel Pinto de Vidal (partido colorado). Estas dos mujeres se convirtieron en las primeras senadoras, no solo del Uruguay, sino de toda Sudamérica.

El decreto $\mathrm{N}^{\circ} 30.815$ del 1 de julio de 2004 de la Junta Departamental de Montevideo designa en su artículo $5^{\circ}$, "con el nombre de PLAZUELA DRA. ISABEL PINTO DE VIDAL, al espacio libre ubicado en Mariano Soler, Pedro Margat y Luisa Domínguez"38.

\section{LOS AÑOS POSTERIORES A LA CONSTITUCION DE 1934 HASTA LA ACTUALIDAD}

Como hemos mencionado, la disposición constitucional no ha variado desde la Constitución de 1934 a la actualidad. Es así que en nuestra actual Constitución del año 1967 en su artículo 74 establece (en igual redacción que el artículo 65 de la Constitución de 1934) que son: "Ciudadanos naturales, todos los hombres y mujeres nacidos en cualquier punto del territorio de la República (...)”.

${ }^{36}$ La Ley de Derechos Políticos de la Mujer N 8.927 del 16 de diciembre de 1932, no solo reconoció el derecho de la mujer al voto tanto en materia nacional como municipal, sino que también sustituyó varios artículos de la Ley de Registro Cívico para poder reorganizar los planes para la inscripción, los lugares de actuación y duración de funcionamiento de las Oficinas inscriptoras delegadas, y sustituyó también otros artículos de la Ley de elecciones. Uno de los artículos sustituidos de la Ley de Registro Cívico, fue el artículo 33, que adoptó la siguiente redacción: "Las Juntas Electorales formaran, dentro de los sesenta dias siguientes a la sanción de esta ley y por dos tercios de votos de sus componentes, un plan de inscripción para el próximo período, sobre la base de las zonas y distritos actuales (...) Esta calificación se publicará en los diarios de cada Departamento, de distinta filiación política, en los que también se establecerán los límites de cada circuito. Contra esta clasificación podrá reclamarse antes del 30 de setiembre de 1934 $y$ en lo sucesivo, en cualquier época, antes del 30 de Setiembre del año en que haya elecciones (...)".

37 SAETTONE MONTERO, MARIELLA. "Derechos de la mujer - participación política" en Noveno Coloquio de Derecho Público, Homenaje al Dr. Héctor Gros Espiell. Editor José Aníbal Cagnoni, Montevideo, 2003.

38 Disponible en: http://www.montevideo.gub.uy/asl/sistemas/Gestar/resoluci.nsf/0bfcab2a0d22 bf960325678d00746391/7625e01e24b36b5c03256f0800592a53?OpenDocument Fecha de consulta: 10 de octubre de 2018. 
Cabe destacar que luego del reconocimiento de los derechos políticos, la mujer amplió su lucha hacia la consagración de los derechos civiles. Fue así que el 18 de setiembre de 1946 se aprobó la Ley $\mathrm{N}^{\circ} 10.783$ de Derechos Civiles de la Mujer.

Esta ley, como lo establece su artículo primero, consagra la igualdad de derechos civiles entre el hombre y la mujer. Recordemos que la mujer, hasta ese momento, era considerada incapaz, no podía ejercer la patria potestad de sus hijos menores de edad, a menos que enviudara, debía obediencia a su marido, no podía contratar ni comparecer en juicio sin licencia de su marido, entre otras restricciones. En virtud de esta ley, se derogaron diversas disposiciones del Código Civil Uruguayo y verdaderamente se equipararon los derechos entre la mujer y el hombre.

En los años posteriores a 1946, el camino que se ha transitado en relación a los derechos políticos ha sido el de la efectiva participación política de las mujeres en nuestro país.

En el ámbito del Derecho Internacional de los Derechos Humanos, Uruguay ha aprobado leyes que incorporan al derecho interno instrumentos internacionales que abordan la temática de los derechos de la mujer. Corresponde mencionar, a nivel universal, el Pacto Internacional de Derechos Civiles y Políticos aprobado por Ley Nº 13.751 en 1969 y la Convención para la Eliminación de Todas las Formas de Discriminación contra la Mujer (CEDAW) que entró en vigencia en el año 1981 y fue aprobada por Decreto Ley $\mathrm{N}^{\circ}$ 15.164. A nivel regional, la Convención Americana sobre Derechos Humanos aprobada en el año 1985 por Ley N 15.737 y la Convención Interamericana para Prevenir, Sancionar y Erradicar la Violencia contra la Mujer, "Convención de Belém do Pará”, adoptada por la Asamblea General de la OEA en el año 1994 y aprobada por Ley № 16.735.

En derecho interno destacamos las siguientes leyes que buscaron facilitar el acceso de la mujer al ámbito político y la real igualdad en todas las áreas de manifestación cívicopolítico.

En el año 2009 se aprobó la Ley N 18.476, comúnmente denominada "ley de cuotas", la que fue modificada posteriormente por la Ley $N^{\circ} 19.555$ en el año 2017. En el artículo 1 (en la redacción dada por esta última ley) se establece:

"Declárase de interés general la participación equitativa de personas de ambos sexos en la integración del Poder Legislativo, de las Intendencias, de las Juntas Departamentales, de los Municipios, de las Juntas Electorales y en los órganos de dirección de los partidos políticos”.

Y en su artículo 2 (en la redacción dada por la Ley $\mathrm{N}^{\circ} 19.555$ ) se dispuso:

"A los efectos establecidos en el artículo anterior y para las elecciones que se convoquen conforme a lo establecido en las Disposiciones Transitorias literales W) y Z) de la Constitución de la República, y en toda elección de primer grado que se celebre para la integración de las autoridades nacionales, departamentales y municipales de los partidos políticos, se deben incluir, en las listas o nóminas correspondientes, personas de ambos sexos, en cada terna de candidatos, titulares y suplentes en el total de la lista o nómina presentada. La presente disposición también regirá para las elecciones de segundo grado a efectos de integrar los respectivos órganos de dirección partidaria.

A su vez, y para las elecciones nacionales, departamentales y municipales, cada lista de candidatos a la Cámara de Senadores, a la Cámara de Representantes, a las Juntas 
Departamentales, a los Municipios y a las Juntas Electorales deberá incluir en su integración personas de ambos sexos en cada terna de candidatos, titulares y suplentes en el total de la lista presentada. El mismo criterio se aplicará a cada lista de candidatos, el titular y sus suplentes a las Intendencias.

En el caso de los departamentos para los cuales la adjudicación de bancas previa a la elección, efectuada por la Corte Electoral, determine que el número de Representantes Nacionales a elegir por el respectivo departamento sea de dos, los candidatos titulares tendrán que ser de diferente sexo, manteniéndose para los candidatos suplentes de los mismos el régimen general de ternas de la presente ley.

A los solos efectos de esta ley y de la conformación de las listas integradas por ambos sexos, el régimen de suplentes mixto de suplentes preferenciales y respectivos (literal d) del artículo 12 de la Ley $N^{\circ} 7.812$, de 16 de enero de 1925, en la redacción dada por el artículo $6^{\circ}$ de la Ley $N^{\circ} 17.113$, de 9 de junio de 1999), se considerará como de suplentes respectivos".

Por otra parte, cabe destacar que Uruguay aprobó una ley integral sobre violencia hacia las mujeres basada en el género (Ley N 19.958 - diciembre 2017). Esta ley incorpora entre sus principios rectores la "igualdad y no discriminación”, estableciendo que:

"Queda prohibida toda forma de distinción, exclusión o restricción basada en el nacimiento, nacionalidad, origen étnico-racial, sexo, edad, orientación sexual o identidad de género, estado civil, religión, condición económica, social, cultural, situación de discapacidad, lugar de residencia u otros factores que tengan por objeto o resultado, el menoscabar o anular el reconocimiento, goce o ejercicio de los derechos humanos y las libertades fundamentales de las mujeres" (artículo 5, literal C).

Asimismo, la precitada ley introduce una nueva manifestación de violencia basada en el género al tipificar la "violencia política", en los siguientes términos:

"Todo acto de presión, persecución, hostigamiento o cualquier tipo de agresión a una mujer o a su familia, en su condición de candidata, electa o en ejercicio de la representación política, para impedir o restringir el libre ejercicio de su cargo o inducirla a tomar decisiones en contra de su voluntad" (artículo 6, literal L).

Sin perjuicio de esta legislación, a la fecha, el número de mujeres parlamentarias en nuestro país continúa siendo reducido. Según el Informe Diagnóstico 2017 elaborado por ONU Mujeres, el Programa de las Naciones Unidas para el Desarrollo (PNUD) e IDEA Internacional, durante el período anterior a la dictadura (de 1985 hasta adelante), la tasa de legisladoras tuvo altibajos, pero siempre fue baja. En las elecciones de 1984, que marcaron la transición hacia la democracia, no se eligió a ninguna mujer como titular. A partir de las elecciones siguientes, se verificó un aumento sostenido de la presencia de legisladoras. En la elección del año 1989 solo fueron elegidas mujeres en la Cámara Baja y ninguna en el Senado; las mujeres recién entraron a la Cámara Alta en 1994. Luego de las elecciones de 2014 (primera vez en que se utilizó la "ley de cuotas"), las elegidas como titulares alcanzaron el 19.4 \% en ambas cámaras, el porcentaje más alto en la historia de Uruguay $^{39}$. De todas formas, y si bien el número de legisladoras se incrementó en las elecciones del año 2014, "la tasa de mujeres legisladoras sigue siendo una de las más bajas

${ }^{39}$ Ob. Cit. nota 39, pág. 26. 
en la región y está muy lejos de los grados de paridad alcanzados por Bolivia o Ecuador, o de los superiores al $30 \%$ que han logrado -hace ya varios años- paises con desarrollos similares al uruguayo como Argentina y Costa Rica" ${ }^{\text {"40 }}$.

En definitiva, y sin perjuicio del reconocimiento y consagración de la igualdad formal entre hombres y mujeres desde el punto de vista jurídico, son notorias las dificultades de la mujer en el acceso a los cargos de poder y en la esfera política en general. Aún resta camino por transitar para la efectiva vigencia de los derechos políticos reconocidos a la Mujer.

\section{BIBILIOGRAFÍA CONSULTADA}

ALVAREZ VIGNOLI DE DEMICHELI, SOFIA. Derechos civiles y políticos de la mujer. Discurso pronunciado en la Tercera Comisión de la VII Conferencia Panamericana en 1933, Montevideo, 1934.

AMARILLO, Solana; DELOS, Gisele y FERNANDEZ, Jessika. "Sufragio femenino" en Revista de la Facultad de Ciencias Juridicas. Vol. 2, N², 2009.

BRUM, BALTASAR. Los derechos de la mujer: reforma a la legislación civil y política del Uruguay. Editor José María Serrano, Montevideo, 1923

DELIO MACHADO, Luis. "Los derechos políticos de la mujer: el debate en torno al sufragio" en Revista de la Facultad de Derecho, No. 13 (enero-junio 1998).

FRUGONI, EMILIO. La mujer ante el Derecho. Los derechos políticos de la mujer. Editorial Indoamericana, Montevideo, 1940.

JIMÉNEZ DE ARÉCHAGA, Justino E. El Voto de la Mujer: su inconstitucionalidad. Peña hermanos Impresores, Montevideo, 1915.

JIMENEZ DE ARÉCHAGA, JUSTINO. La Constitución Nacional. Tomo I.

GROS ESPIELL, HÉCTOR. Evolución constitucional del Uruguay. FCU, Montevideo, 3era. Edición, 2003

LUISI, Paulina (Dir.) La mujer uruguaya reclama sus derechos políticos. Alianza Uruguaya y Consejo de Mujeres, Montevideo, 1929.

REVISTA ACCIÓN FEMENINA. Agosto 1917. Número 2. Año I. Montevideo.

REVISTA HISTÓRICA. Tomo LIV, Año LXXV, Nos. 160-162, Publicación del Museo Histórico Nacional. Pivel Devoto, Juan - Director. Año 1982

SAETTONE MONTERO, MARIELLA. "Derechos de la mujer - participación política" en Noveno Coloquio de Derecho Público, Homenaje al Dr. Héctor Gros Espiell. Editor José Aníbal Cagnoni, Montevideo, 2003.

URUGUAY: una democracia consolidada aún muy lejos de la paridad. Diagnóstico sobre las condiciones para ejercer el derecho a la participación política de las mujeres. Informe Diagnóstico 2017. ONU Mujeres, Programa de las Naciones Unidas para el Desarrollo (PNUD) e IDEA Internacional.

VIGIL, MERCEDES. "La vanguardia feminista" en Matilde, la mujer de Batlle. Editorial Planeta, Montevideo, 1era. Edición, 2003.

Fecha de recepción: 10 octubre 2018.

Fecha de aceptación: 1 noviembre 2018.

40 Uruguay: una democracia consolidada aún muy lejos de la paridad. Diagnóstico sobre las condiciones para ejercer el derecho a la participación política de las mujeres. Informe Diagnóstico 2017, presentado el 4 de setiembre de 2018 por ONU Mujeres, el Programa de las Naciones Unidas para el Desarrollo (PNUD) e IDEA Internacional. ONU Mujeres, PNUD e IDEA Internacional, pág. 19. Disponible en: http://www.uy.undp.org/content/uruguay/es/home/library/poverty/Publicacion_Atenea-Uruguay .html Fecha de consulta: 3 de noviembre de 2018. 